\title{
Sensitivity of discharge projections to potential evapotranspiration estimation in Northern Tunisia
}

\author{
Hamouda Dakhlaoui ${ }^{1,2,3}$ (D) Jan Seibert ${ }^{3,4} \cdot$ Kirsti Hakala $^{3,5}$ \\ Received: 7 August 2018 / Accepted: 23 November 2019 / Published online: 5 March 2020 \\ (C) The Author(s) 2020
}

\begin{abstract}
Tunisia has a long history of coping with water scarcity, and the quantification of climate change impacts on runoff is important for future water management. A major requirement for such studies is an estimation of potential evapotranspiration (PET), which is challenging as many regions often lack the observational data needed for physically based PET equations. In this study, different PET estimation approaches were used to study the impact of PET estimation on discharge projections for catchments in Northern Tunisia. Discharge was simulated for five catchments using three rainfall-runoff models (RRMs): HBV, GR4 and IHACRES. A general differential split sample test (GDSST) was used for an RRM robustness evaluation based on subperiods with contrasting climatic conditions for the 1970-2000 period. Three cases with varying PET were considered: (1) daily calculated PET, (2) long-term daily mean PET with the same values for calibration and validation periods (calculated over the calibration period) and (3) long-term daily mean PET varying between calibration and validation periods (calculated over the calibration and validation period separately). Over the historical period, the comparison between cases 1 and 3 showed little impact of reduced PET information on the RRM performance and robustness. The comparison of cases 2 and 3 indicated a limited impact of varying PET between calibration and validation on the RRM results. The impact of varying levels of PET information on hydrological projections was also analysed over two future 30-year periods: mid-term period (2040-2070) and long-term period (2070-2100), with two representative concentration pathway scenarios (RCPs 4.5 and 8.5), by comparing cases 1 and 2. The projected discharge with constant PET (case 2) was generally lower than the projected discharge with variable PET (case 1) but the difference in volume change did not exceed $9 \%$ for both the time period and the RCP scenario considered. While PET slightly increased under the different climate change scenarios, actual evapotranspiration (AET) was found to decrease. These opposite trends of PET and AET can be attributed to the projected decrease in precipitation. Overall, our results demonstrate that discharge, in semi-arid regions like Northern Tunisia, is not sensitive to PET estimates since AET is mainly controlled by the availability of soil moisture. This finding is useful for performing studies of climate change impact on hydrological cycles in arid regions, as our study shows that simple PET estimation is a valid approach for such studies.
\end{abstract}

Keywords Rainfall-runoff modelling $\cdot$ PET $\cdot$ GDSST $\cdot$ Hydrological projection $\cdot$ EURO-CORDEX $\cdot$ Tunisia

This article is part of the Topical Collection on Climate change impacts in the Mediterranean

Electronic supplementary material The online version of this article (https://doi.org/10.1007/s10113-020-01615-8) contains supplementary material, which is available to authorized users.

Hamouda Dakhlaoui

hammouda.dakhlaoui@laposte.net

$\triangle$ Jan Seibert

jan.seibert@slu.se; jan.seibert@geo.uzh.ch

Kirsti Hakala

kirsti.hakala@unimelb.edu.au

1 LMHE, Ecole Nationale d'Ingénieurs de Tunis, Université Tunis El Manar, BP 37 Le Belvedère, 1002 Tunis, Tunisia
2 Ecole Nationale d'Architecture et d'Urbanisme, Université de Carthage, Sidi Bou Said, Tunisia

3 Department of Geography, University of Zurich, Zürich, Switzerland

4 Department of Aquatic Sciences and Assessment, Swedish University of Agricultural Sciences, Uppsala, Sweden

5 Department of Infrastructure Engineering, University of Melbourne, Victoria, Australia 


\section{Introduction}

Tunisia has a long history of coping with water scarcity, characterized by extended periods of drought as well as persistent issues with water quality and over-extraction. Northern Tunisia produces approximately $83 \%$ of the surface water in Tunisia while providing several water transfers to the eastern and the southern parts of the country (ITES 2014). Recent climate change scenarios project around a $20 \%$ decrease in total precipitation and $\mathrm{a}+1{ }^{\circ} \mathrm{C}$ to $+3{ }^{\circ} \mathrm{C}$ increase in mean annual temperature by 2050 compared with the 1971-1990 period (Terink et al. 2013; Tramblay et al. 2017). This could result in a substantial decrease in fresh water availability in the future, which would have a dramatic impact on various socioeconomic sectors (e.g. agriculture and tourism), and implies significant risks for ecosystems and for human well-being (Cramer et al. 2018). Adaptation to climate change is therefore crucial, and this level of susceptibility calls for an understanding of local climate change impacts on water resources. Rainfall-runoff models (RRMs), forced by regional climate models, are widely used to assess the hydrological impacts of climate change at the catchment scale (e.g. Ruelland et al. 2015; Hakala et al. 2019). Evapotranspiration is an essential part of the water balance at the catchment scale, especially for the Mediterranean region where around $90 \%$ of the annual rainfall can be lost through evapotranspiration (Wilcox et al. 2003). Therefore, to accurately simulate discharge, the estimation of potential evapotranspiration (PET) is required as an input. However, studies that evaluated the hydrological impacts of climate change on water resources in the Southwest Mediterranean Rim region (e.g. Ruelland et al. 2015; Sellami et al. 2015; Marchane et al. 2017) did not consider the sensitivity of PET estimation on hydrological projections.

Although a bias in PET estimation may be compensated during the calibration process by model parameters (Oudin et al. 2005a), it can have a considerable impact for periods outside calibration, especially in the case of climate variability. This, in turn, can lead to significant errors when modelling hydrological peaks and recession characteristics (Andréassian et al. 2004). The sensitivity of discharge to PET estimation may depend on the climate conditions, with a corresponding greater sensitivity within wet regions (Sperna Weiland et al. 2012; Seiller and Anctil 2014) than dry regions (Sheffield et al. 2012; Kingston et al. 2009). Recently, Guo et al. (2017) found that discharge sensitivity to PET in five catchments in climatologically different regions of Australia depends on both PET estimation and the methods used by hydrological models to convert PET to actual evapotranspiration (AET).

PET values must be expected to vary for a changing climate (Prudhomme and Williamson 2013; Seiller and Anctil 2014), and the estimation of PET could be an additional source of uncertainty for hydrological projections. Several studies show that the impacts of climate change on discharge depend on the PET formula used (Seiller and Anctil 2016; Bae et al. 2011; Sperna Weiland et al. 2012). Physically-based PET formulas could theoretically have the potential to provide more accurate PET estimations compared with temperaturebased formulas because they consider the different climate drivers that affect the evaporative demand (Prudhomme and Williamson 2013). Assuming that anthopogenic $\mathrm{CO}_{2}$ emissions will keep on influencing temperatures over the next century (IPCC 2013), the use of temperature-based formulas results in a substantial increase in projected PET. However, several studies have investigated the pan evaporation paradox (Li et al. 2013) and have shown that future potential evaporation could be attenuated by the change in other climate variables such as the expected increase of air humidity (Wang et al. 2017) and decreasing trend for wind speed (Mansour et al. 2017).

Although there are inherent limitations to using temperature-based PET formula, it is often not feasible to alternatively use a physically based formula due to a large number of climate variables required to fulfil such equations and a lack of observational data. In this regard, data availability is a particular limitation in regions such as Northern Tunisia due to limited climate records (e.g. Jabloun and Sahli 2008; Aouissi et al. 2016). The use of temperaturebased PET formulas is, thus, often considered the only possible solution. It is therefore not surprising that the hydrological projection studies performed over Northwest Africa (Maghreb region) have mainly utilized temperature-based formulas (Marchane et al. 2017; Tramblay et al. 2016; Ruelland et al. 2015). Given the widespread use of such simple formulas, the impact of the use of temperature-based PET formulas on hydrological projections, rather than physically based PET formulas, needs to be explored in this region of the world. For this purpose, it would, in theory, be ideal to compare the hydrological projections generated with hydrological models forced by temperature-based PET formula to those forced by physically based PET formulas. However, in the context of data scarcity, such a comparison is not feasible. Therefore, this study employs a novel methodology, with low data requirements, to test the sensitivity of hydrological projections to PET estimation.

The main goal of the present study is to provide a methodology for the assessment of the potential impact of PET estimation on the prediction capacity of RRMs and on hydrological projections, within a data-scarce region. Additionally, this study aims to provide a first quantification on the impact of climate change on discharge in Northern Tunisia, and thereby encourage additional climate change impact studies for Tunisia and regions with similar climate and data availability. To this end, this study addresses the three following research questions: 
- What is the sensitivity of RRM to PET estimation in an arid region?

- What are the likely impacts of climate change on the hydroclimatology of Northern Tunisia?

- How sensitive are the trajectories of hydrological projections to PET estimation?

\section{Data and models}

\section{Study areas}

Five catchments located in Northern Tunisia were selected for this study (Fig. 1). The discharge can be considered 'natural' since these catchments are located upstream from major hydraulic installations, such as dams and water transfers. The study catchments are situated within a semi-arid to humid Mediterranean climate with a warm and dry season which extends from June to August (Henia 2008). When averaged over the catchment areas, PET always exceeds precipitation (Fig. 1). In this region, actual evapotranspiration is mainly limited by water availability for most parts of the year (Tramblay et al. 2017). The catchments are located in a pivotal area, which serves a strategic role as a water supplier for the rest of the country (Ben Fraj et al. 2019). Some of the streams feed into wetlands (Lake Ichkeul, Sebkhet Soliman, etc). Lake Ichkeul, and its marshes, is one of the most important wetlands of the western Mediterranean basin and is an essential stopover point for birds migrating between Eurasia and SubSaharan Africa (Hamdi et al. 2012).

\section{Hydrological models}

Discharge simulations have been shown to be sensitive to the methods used by hydrological models to convert PET to AET (Guo et al. 2017). This encouraged us to use different model structures for this study. Three simple bucket-type RRMs, all running at the daily time step, were used: GR4J (Perrin et al. 2003), HBV (Lindström et al. 1997) and IHACRES (Jakeman et al. 1990). These models differ in the way they conceptualise hydrological processes and in their complexity: GR4J has four parameters, whereas HBV has eight and IHACRES six. These models differ in how AET is computed from PET, which allows for an interesting inter-comparison of model simulations. In GR4, a production function accounts for precipitation and potential evapotranspiration and determines the effective precipitation that contributes to flow and supplies the

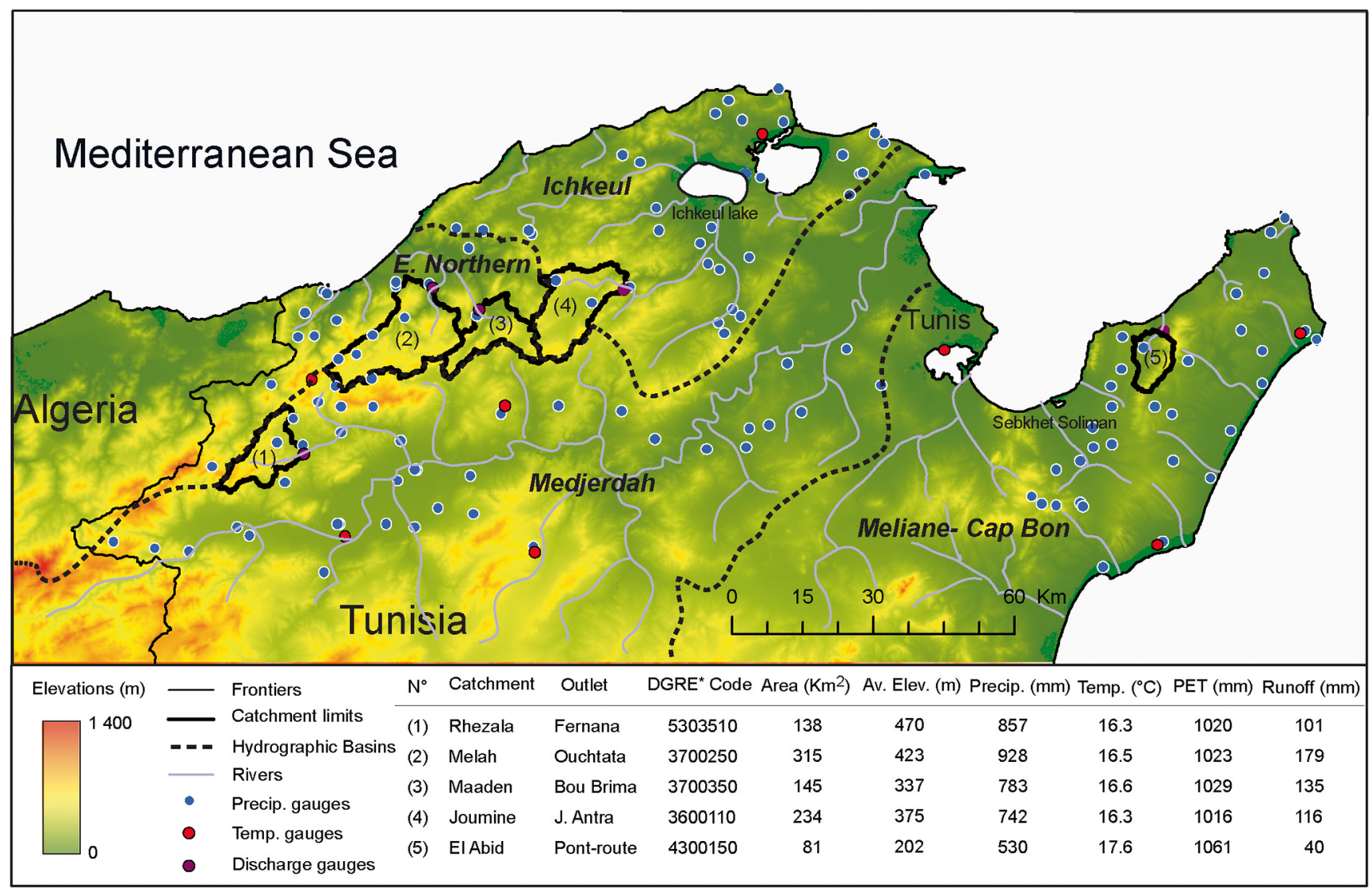

Fig. 1 Locations of study catchments are indicated by a bold black line along with the locations of the precipitation (blue circles), temperature (red circles) and stream flow gauges (purple circles). The main hydro-climatic characteristics are averaged over the period 1970-2000 
reservoir. AET is calculated according to a parabolic function of soil moisture. Only one free parameter is dedicated to the production module. In HBV, AET equals PET when the soil storage is filled to a certain fraction (as specified by a model parameter) and decreases linearly for smaller soil water storage values. In IHACRES, the input rainfall is partitioned explicitly into drainage, evapotranspiration, and changes in catchment moisture. AET is calculated according to an exponential function of soil moisture. IHACRES allocates two free parameters to the production module. All three models have recently been used successfully to simulate discharge from other catchments in Tunisia (Bargaoui et al. 2008; Dakhlaoui et al. 2009, 2012; Abbaris et al. 2014). Additional information for each model can be found in Tab. S1 (Online Resources). The model parameters were calibrated using the Shuffle Complex Evolution algorithm (Duan et al. 1992) and the Kling-Gupta Efficiency (KGE, Gupta et al. 2009) as objective functions. The hydrological models were run at a daily time step, but their efficiency evaluation was performed on 10-day averages, since our study primarily focuses on water resources rather than on the day-to-day variation and the averaged discharge values were more reliable than the daily values. Model performance during validation was evaluated based on the Nash-Sutcliffe Efficiency (NSE, Nash and Sutcliffe 1970) and the relative volume error (VE) in mean discharge.

\section{In situ hydro-climatic data}

In total, 123 rain gauges situated in the study area were used. The selected gauges have some missing data but do not exceed $30 \%$ of the total data over the period of 1970-2000, thus providing a stable, coherent network of measurements for the spatial interpolation of rainfall forcing (see Fig. 1). Eight meteorological stations with daily temperature data were used. Climate forcing data was generated by spatially interpolating the station data, on a 2-km horizontal grid spacing, using an inverse distance weighting technique. Based on the available data, the approach of Oudin et al. (2005b) was chosen to estimate PET. This formula is based on estimated clear daily sky solar radiation and mean daily air temperature. It is expressed as follows:

$$
\begin{gathered}
E_{\mathrm{pot}}=\frac{R_{e}}{\lambda \rho} \frac{T_{a}+5}{100} \text { if } T_{a}>-5 \\
E_{\mathrm{pot}}=0 \text { otherwise }
\end{gathered}
$$

where $E_{\text {pot }}$ is the rate of potential evapotranspiration $\left(\mathrm{mm}\right.$ day $\left.{ }^{-1}\right) ; R_{e}$ is extraterrestrial radiation $\left(\mathrm{MJ} \mathrm{m}^{-2}\right.$ day $\left.^{-1}\right)$; $\lambda$ is the latent heat flux $\left(\mathrm{MJ} \mathrm{kg}^{-1}\right) ; \rho$ is the density of water $\left(\mathrm{kg} \mathrm{m}^{-3}\right)$ and $T_{a}$ is mean air temperature $\left({ }^{\circ} \mathrm{C}\right)$.

\section{High-resolution climate simulations and bias correction of climate variables}

Different daily temperature and precipitation time series, simulated by eleven GCM-RCMs (general circulation models forcing regional climate models), were obtained from the Coordinated Regional Downscaling Experiment (CORDEX; www.cordex.org). Given the location of the catchments, GCM-RCMs from the European domain were selected (EURO-CORDEX, http://www.euro-cordex.net/). EUROCORDEX simulations are the most recent high-resolution climate projections for the European domain with a $0.11^{\circ}$ resolution ( $12.5-\mathrm{km}$ horizontal grid spacing). The GCM-RCM historical simulations span over the period 1970-2005, and the future period was divided over two periods: mid-term (2040-2070) and long-term (2070-2100). Two representative concentration pathway (RCP) scenarios were considered for the projections: RCP 4.5 and RCP 8.5 (IPCC, 2013). RCP 4.5 assumes that global annual greenhouse gas emissions peak between around 2040, then decline thereafter. In RCP 8.5, emissions continue to rise throughout the twenty-first century (Meinshausen et al. 2011).

\section{Methods}

\section{Impact of potential evapotranspiration estimation on rainfall-runoff model performance and robustness}

To evaluate the sensitivity of hydrological projections to PET estimation, we first assessed the sensitivity of RRM to PET estimation under historical climate conditions, using a differential split sample test (DSST; Klemeš 1986). This step is needed so that we may check whether it is reasonable to extrapolate our methods to future period. We propose an evaluation of the sensitivity of discharge simulations to PET formulation, based on a comparison of three cases of PET estimations (see Fig. S1 in Online Resources):

- Case 1: Daily PET calculated over the calibration and validation period separately (without averaging).

- Case 2: Long-term daily mean PET with the same values for calibration and validation periods (PET calculated over the calibration period and then averaged to create a series of 366 values, which were repeated for both the calibration and validation period).

- Case 3: Long-term daily mean PET varying between calibration and validation periods (PET calculated over the calibration period and validation period separately. The two sets of daily values were then averaged to create two sets of 366 values, which were then used for calibration and validation separately). 
Over the historical period, the comparison of RRM performance and robustness between cases 1 and 3 allowed for an evaluation of the impact of long-term averaging of PET on the hydrological model performance and robustness. The comparison of these two cases was also chosen in order to indicate whether the long-term averaging of PET was acceptable for hydrological projections. The comparison of cases 2 and 3 allowed for the evaluation of the impact of keeping PET the same versus allowing it to change between calibration and validation periods on RRM performance.

The evaluation of RRM robustness was performed using DSST (Klemeš 1986). DSST is the typical method to investigate RRM robustness under climate variability (Seibert 2003; Hartmann and Bárdossy 2005; Fowler et al. 2016; Dakhlaoui et al. 2017; Vormoor et al. 2018). It consists of calibration and validation exercises of RRM under climate-contrasted conditions. The idea behind performing a DSST is that the errors made by extrapolation from certain observed climate conditions to different observed conditions might correspond to the errors made when using observed data for calibration and extrapolating this to future climatic conditions (Seibert 2003). Dakhlaoui et al. (2019) proposed a generalization of DSST called general differential split sample test (GDSST) based on an oriented bootstrap applied to discontinuous subperiods, which allows for a large number of calibration and validation exercises and a better sample spread, with more contrasted subperiods (in precipitation and temperature) compared with previous techniques. This technique helps with the evaluation of RRM robustness for a broad range of climate conditions. We used the GDSST as proposed by Dakhlaoui et al. (2019) to generate 100 climate-contrasted subperiods (precipitation and temperature) over the observed period 1970-2000 for each catchment. The duration of each subperiod was 15 years, which could be non-consecutive. We used each subperiod as a calibration period for the RRM and evaluated the performance of hydrological predictions in the complementary subperiod. In contrast to other studies, which used continuous calibration and validation periods for the DSST (e.g. Coron et al. 2012; Brigode et al. 2013), we used discontinuous subperiods but always used entire hydrological years. The initial conditions for each hydrological year were checked so that they are not significantly affected by the climatic conditions of the preceding year. It should be noted that the climate of Northern Tunisia has a long dry season (June to August) during which most of the soil moisture is evaporated resulting in almost the same (dry) initial conditions in the following hydrological year.

We performed the calibration and validation exercise for each catchment for the 100 GDSST subperiods for cases 1, 2 and 3 separately. The model transferability was evaluated by the change in NSE and VE between the calibration and validation periods. NSE was based on a ratio between the squared model error and the variance of observed flows. Hence, any changes in variance or volumes between contrasted climatic periods such as dry/wet could have an impact on the comparison of results.
Performance measures like NSE for different simulation time periods cannot easily be compared. Therefore, we evaluated model transferability by calculating the differences between NSE resulting from calibration period (receiver) and the NSE calculated over the same period but with parameters provided by model calibration on validation subperiods (donor). The same was done for VE. We evaluated model transferability in terms of NSE and VE as a function of the change in total precipitation and mean temperature $(\Delta \mathrm{P}$ and $\Delta \mathrm{T})$ between the validation and calibration periods. To study the origin of the differences in RRM performances between the different cases, we also looked at the differences in terms of PET and AET between the calibration and validation periods.

\section{Projections of climate change impacts}

Quantile mapping (QM) was utilized as a bias correction method to correct the daily precipitation and temperature of the GCM-RCMs. Previous studies have shown QM to outperform other bias correction methods (Teutschbein and Seibert 2012; Chen et al. 2013). The aim of QM is to correct the distribution of the climate model data so that it matches the distribution of the observational data. It consists of estimating quantiles for both observation and modelled climate variable under a control period. A transfer function is then created by interpolation between corresponding quantile values, which is applied to the projected climate variable. Here, the cumulative distribution functions (CDFs) of observed and modelled climate variable were estimated using empirical percentiles. Values in between the percentiles were approximated using linear interpolation. In cases where new GCM-RCM values (such as from the projected period) were larger than the control values used to estimate the empirical CDF, a linear regression fit was used to extrapolate beyond the range of observations. The transfer function of the QM was based on a 30-year control period (1970-2000), which is the recommended time length for climate applications (WMO, 2011). The transfer function of the QM was then applied to bias correct the GCM-RCMs projected daily precipitation and temperature over the mid-term (2040-2070) and long-term (2070-2100) future periods for the two RCPs. The RRMs were forced by the bias-corrected GCM-RCM climate data (precipitation and temperature) to generate the projected discharge.

\section{Evaluating the sensitivity of hydrological projections to potential evapotranspiration estimation}

Two cases were used to compare the impact of PET estimation on hydrological projections: (i) case 1: PET calculated at the daily scale, using the Oudin formula, over the historical and future period. In case 1, the observed temperature is used for the historical period, and GCM-RCM bias-corrected temperature is used for the calculation of PET for the future periods. (ii) Case 2: The 
long-term daily mean PET is calculated and used for RRM calibration over the historical period and also repeated over the future time periods.

Case 1 is meant to represent a situation where a simple temperature-based PET formula, which is only sensitive to change in temperature, is used. We hypothesised that this case would result in the highest future increase in PET, due to the increasing of temperatures found within the RCP scenarios. Case 2 represents a different situation, similar to the pan evaporation paradox, which expects an attenuation of future PET by the future change in other climatic drivers, until stabilisation. This kind of attenuation of future PET by other climatic drivers could be addressed only by a physically based PET formula. The comparison of these two extreme cases allows for the evaluation of the sensitivity of hydrological projections to the PET estimation and assessing the potential loss in hydrological projection caused by using a simple temperature-based PET formula rather than a more physically based PET formula.

We considered the variance of the hydrological projections as an estimate of their uncertainty and used an analysis of variance (ANOVA, Hawkins and Sutton 2009) technique to quantify the contribution of uncertainty stemming from different elements of the modelling chain to the total uncertainty. More specifically, this provides a sensitivity test of whether PET estimation contributes to the total uncertainty compared with the other sources of uncertainty. A similar analysis (using ANOVA) was performed by Addor et al. (2014) to quantify the contribution from different aspects of the modelling chain to hydrological projection uncertainty for six Swiss catchments; however, that study did not investigate PET estimation uncertainty. Following this example, and extending it to additionally take PET estimation uncertainty into account, six sources of uncertainty were compared: (1) emission scenarios (RCP 4.5 and RCP 8.5), (2) GCM-RCMs, (3) hydrological models (HBV, GR4 and IHACRES), (4) PET estimation (cases 1 and 2), (5) the sum of the significant interaction between factors and (6) residual error. The fraction of explained variance of the discharge change for the two 30-year future periods (2040-2070 and 2070-2100) compared with the reference period (1970-2000), by each factor, was computed by dividing the variance of each factor by the total variance. The analysis was performed for each catchment and each of the two future periods.

\section{Results}

\section{Evaluating the effect of potential evapotranspiration estimation on rainfall-runoff model robustness}

\section{Effect of long-term potential evapotranspiration averaging on rainfall-runoff model robustness}

Our results show that when daily PET (case 1) is compared with long-term daily mean PET (case 3), only minimal differences exist between the PET values. The biggest differences between case 1 and case 3 occur in summer, where discharge generation is at its lowest level during the year. Conversely, the smallest differences were observed in winter, where the generation of discharge is the greatest. A comparison between case 1 and case 3, over the period 1970-2000, for the $\mathrm{O}$. Abid catchment is presented in the Online Resources (Fig. S2). Cases 1 and 3 exhibit similar performances over the calibration period in terms of NSE and VE (Online Resources, Fig. S3), which implies that temporally varying PET and a long-term daily mean PET produce similar discharge time series. Furthermore, this demonstrates the low sensitivity of hydrological models to PET interannual variation.

Figure 2 shows the mean results of GDSST experiments for each case of PET estimation, where $\Delta \mathrm{P}$ and $\Delta \mathrm{T}$ are compared for all catchments. Based on the NSE criterion, the transferability was gradually affected by the decrease in precipitation and the increase in temperature (Fig. 2a). Similarly, the transferability of VE was also more affected by changes in precipitation than in temperature (Fig. 2b). We observed no significant difference in RRM robustness between cases 1 and 3 (Fig. 2a, b). The results shown here are for the GR4 model. However, we observed a similar behaviour between the different models. (Results from HBV and IHACRES are shown in Fig. S4 within the Online Resources.)

To better understand the origin of the difference in RRM robustness between cases 1 and 3, Fig. $2 \mathrm{c}$ and d show the difference in terms of PET and AET between calibration and validation for the GR4 model. The behaviour of PET is shown to be highly correlated to temperature variation, which is expected since temperature is the basis for the calculation of PET using the Oudin formula. However, this is not the case for AET, which is mainly dependent on water availability (i.e. precipitation). Instead, AET increases with a decrease in temperature (Fig. 3).

\section{Effect of potential evapotranspiration estimation on the robustness of rainfall-runoff models}

Similar to the results presented in the previous section, an additional experiment was performed to evaluate the change in RRM robustness between cases 2 and 3 (see Fig. 2a, b for GR4 and Fig. S3 (Online Resources) for HBV and IHACRES). Small differences were found between the robustness of the RRMs when comparing the two cases, in terms of VE (difference between -4 and $+4 \%$ ). For NSE, the difference between the two cases was around zero. The RRMs forced by long-term daily mean PET with the same values for calibration and validation periods tend to overestimate $\mathrm{VE}$ for positive $\Delta \mathrm{T}$, and underestimate $\mathrm{VE}$ for negative $\Delta \mathrm{T}$, compared with the case where PET varies between calibration and validation periods. Figure $2 \mathrm{c}$ and $\mathrm{d}$ show the difference in terms of PET and AET between calibration and validation periods between cases 
a) NSE
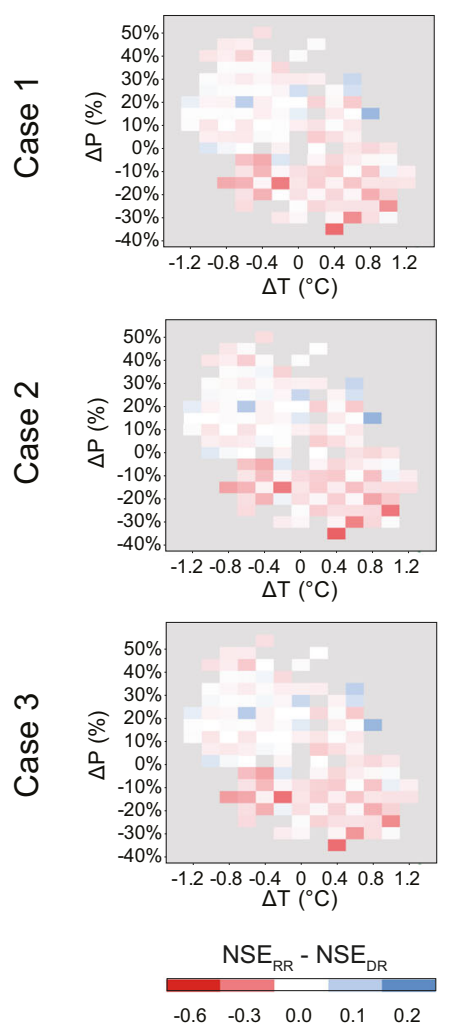

b) VE
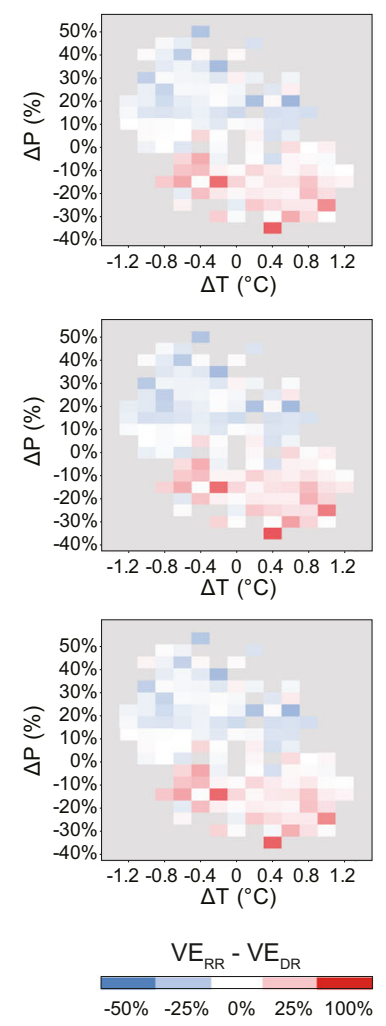

Fig. 2 Evaluation of GR4 model efficiency as a function of change in precipitation and temperature $(\Delta \mathrm{P}$ and $\Delta \mathrm{T})$. Each coloured square represents the mean results for the five catchments. Model transferability was evaluated according to differences in a NashSutcliffe Efficiency (NSE) and $\mathbf{b}$ relative error in mean discharge (VE) c) AET
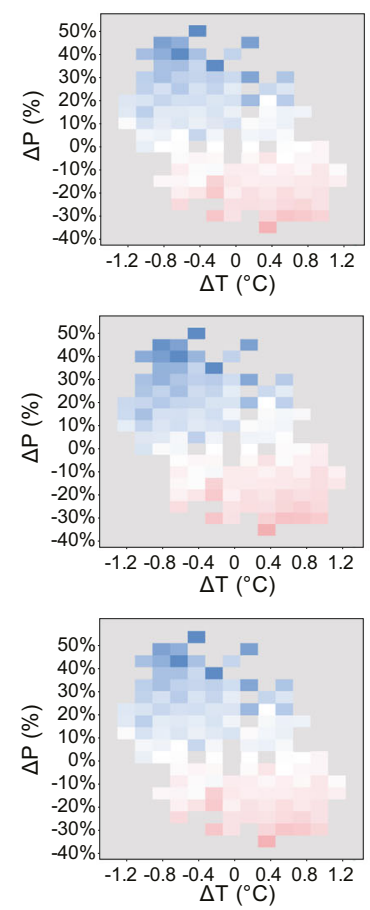

$$
\begin{array}{llll}
\left(\mathrm{AET}_{\mathrm{RR}}-\mathrm{AET}_{\mathrm{DR}}\right) / \mathrm{AET} \mathrm{T}_{\mathrm{DR}} \\
\hline-20 \%-10 \% & 0 \% & 10 \% & 20 \%
\end{array}
$$

d) PET
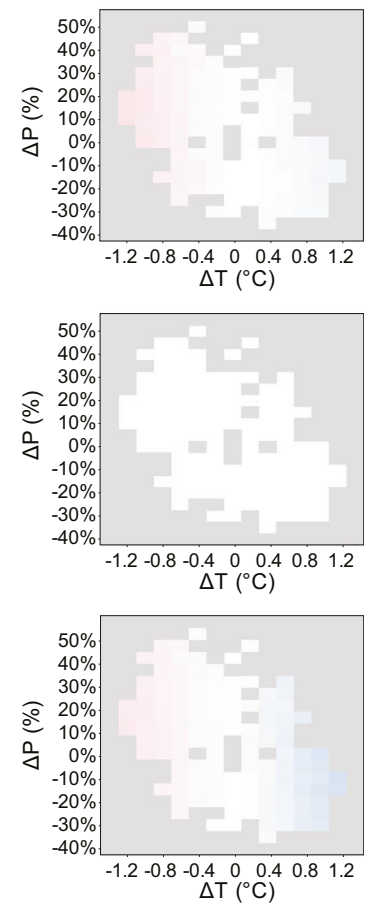

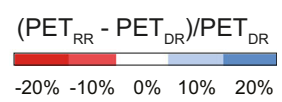

between the receiver (RR, i.e. validation) and the donor (DR, i.e. calibration) periods. The difference in terms of potential evapotranspiration (PET) and actual evapotranspiration (AET) between calibration and validation period is presented in a similar way in $\mathbf{c}$ and $\mathbf{d}$

For PET, over the long term, an increase of +3.5 to $+11 \%$ is projected within the scenario RCP 4.5 , and +8.8 to $+17 \%$ with the scenario RCP 8.5 . Contrary to precipitation, these changes are projected mainly during the summer months. PET changes are likely to have little impact on discharge since there is already very little discharge during the summer. In contrast, the decrease in precipitation amounts during winter months may have a critical impact on water resources. Our results also show that the climate change signal is very different from one GCM-RCM to another; however, all GCM-RCMs depict a warmer future climate and almost all climate models expect dryer conditions for the future (Fig. 4a, b). (Detailed results of the changes can be found within the Online Resources (Fig. S5).)

\section{Evaluating the sensitivity of hydrological projections to potential evapotranspiration estimation}

The median of the hydrological projections for the Maaden catchment, when comparing cases 1 and 2 with three RRMs (Fig. 4d, detailed results for the remaining catchments are presented in Fig. S5 of the Online Resources), shows that, for the mid-term period, the RCP 4.5 scenario results in a 


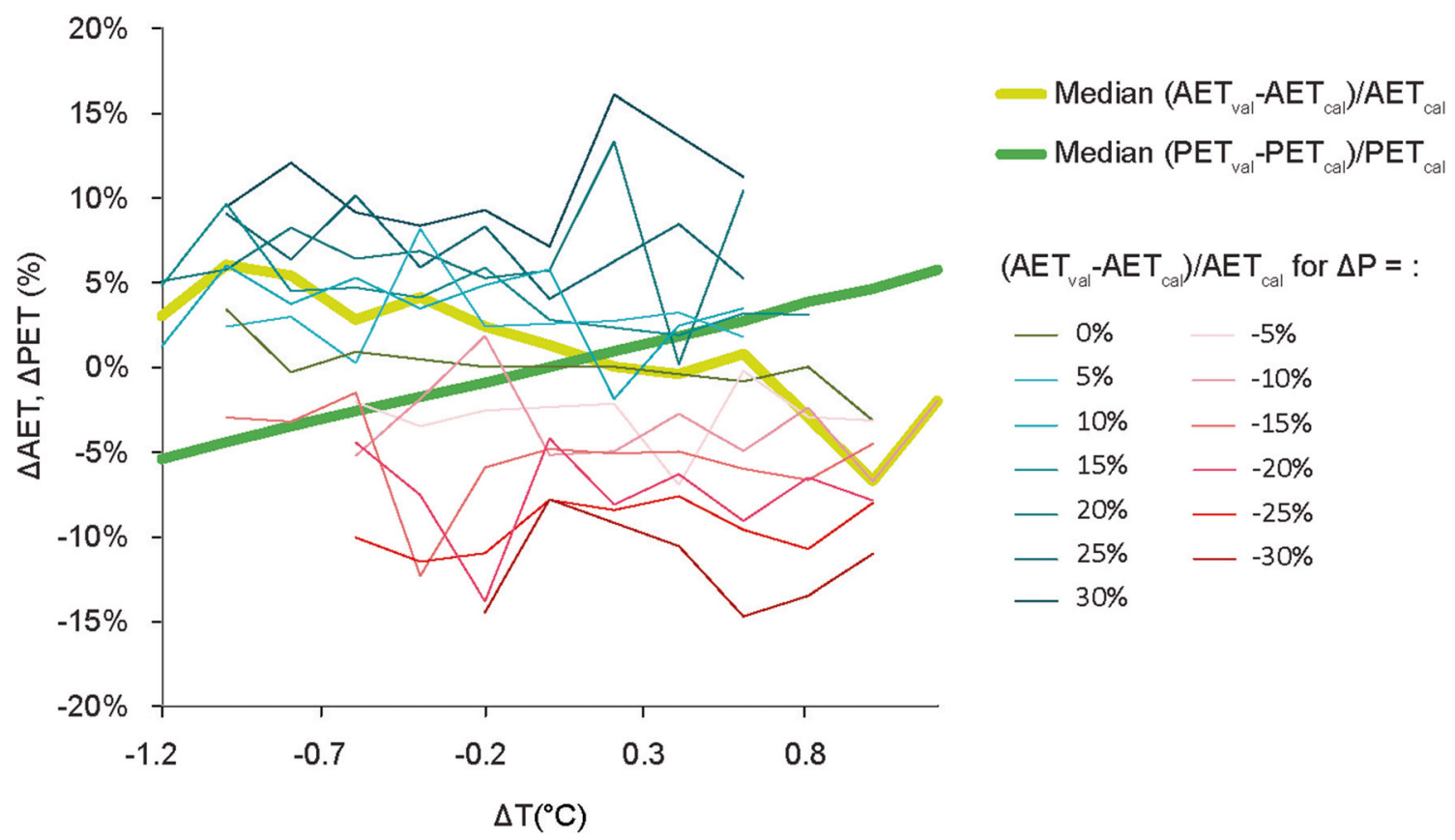

Fig. 3 Change in actual evapotranspiration (AET) and potential evapotranspiration (PET) as a function of change in precipitation and temperature ( $\triangle \mathrm{P}$ and $\Delta \mathrm{T}$ ) between calibration (cal) and validation period (val) for the hydrological model GR4

decrease of discharge of 10 to $30 \%$ and 25 to $38 \%$ for the RCP 8.5 scenario. For the long-term period, a decrease of 20 to $37 \%$ of discharge is expected for RCP 4.5 and 41 to $58 \%$ for RCP 8.5.

However, for case 2, the estimated hydrological impact is by approximately -2 to $-8 \%$ smaller than for case 1 . The difference in mean annual discharge between the two cases is generally under $5 \%$ for the RCP 4.5 (for both the mid-term and long-tern periods) and also for RCP 8.5 for the mid-term period. The difference in volume change between cases 1 and 2 exceeds the $5 \%$ for RCP 8.5 over long-term periods, but it is always less than $10 \%$ (see Fig. S6 within the Online
Resources). These results are robust, meaning that we find similar behaviour amongst the different RRMs.

The decomposition of the projection variance by ANOVA partitioning amongst the six sources of uncertainty shows that the GCM-RCMs are the dominant source of uncertainty. The difference between cases 1 and 2 represents only a small proportion of the variance in the hydrological projections (see Fig. S7 within Online Resources).

The hydrological response of Northern Tunisian catchments shows a high sensitivity to any change in precipitation. The evaluation of the elasticity of discharge to precipitation for the hydrological model GR4 (e.g. change in discharge

\section{a) Rainfall}

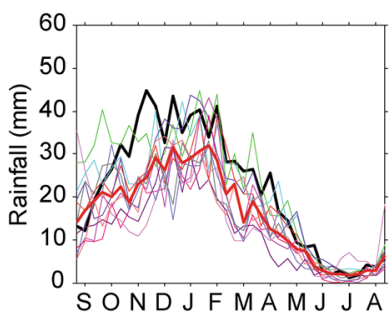

- Obs

- Median GCM-RCMs

- CNRM-CERFACS-CNRM-CM5/CLMCOM-CCLM4-8-17

- CNRM-CERFACS-CNRM-CM5/SMHI-RCA4

- ICHEC-EC-EARTH/CLMCOM-CCLM4-8-17

ICHEC-EC-EARTH/SMHI-RCA4

- ICHEC-EC-EARTHIKNMI-RACMO22E

Fig. 4 Projected (a) rainfall, (b) temperature, (c) potential evapotranspiration $(\mathrm{PET})$ and $(\mathrm{d})$ discharge $(\mathrm{Q})$ for cases 1 and 2, from $\mathrm{HBV}$, IHACRES and GR4J model, for the Maaden catchment, for c) PET
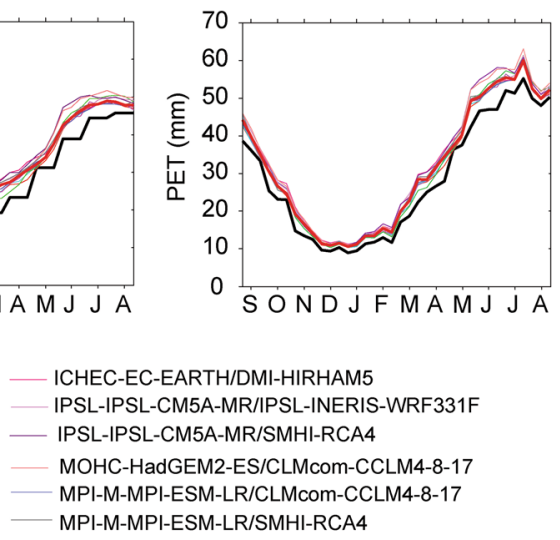

d) Discharge

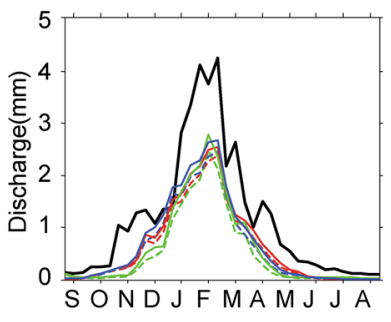

- Q-obs - Q-HBV-Case2

--- Q-HBV-Case1 - Q-HACRES-Case2

-.- Q-HACRES-Case1 — Q-GR4J-Case2

--- Q-GR4J-Case1 representative concentration pathway scenario 8.5 , over the long-term period (2070-2100) and compared with observation over the reference period 1970-2000 (Obs). GCM and RCM names are separated by a slash 
between present and projected climate as a function of the change in precipitation) results in a hydrological multiplication factor of around two (Fig. 5, the results from the other models are included in the Online Resources Fig. S8). In other words, for every unit of precipitation increase or decrease, discharge will change by a factor of 2 . The elasticity curves are similar between cases 1 and 2 and across the different RRMs.

\section{Discussion}

\section{Effect of potential evapotranspiration estimation on the robustness of rainfall-runoff models}

The temporally varying PET (case 1) and long-term daily mean PET (case 3) produced similar RRM performance for the calibration period. This result is supported by several studies (Fowler 2002; Oudin et al. 2005b), although it is more accentuated in Northern Tunisia given the region's semi-arid climate condition and water-limited evaporation.

Our results illustrate a similarity between the different RRM in terms of sensitivity to PET information in spite of their different model structures, and their different formulations of calculating AET. This concept shows that long-term daily averaged PET does not affect RRM prediction capacity needed for hydrological projections. Although this result is supported by Oudin et al. (2005b), it does not match with those obtained by Guo et al. (2017), which showed that, for the case of several Australian catchments, the different evaporation process representations in conceptual rainfall-runoff models can have substantial impacts on discharge projections under a changing climate. One explanation for

a) GR4J

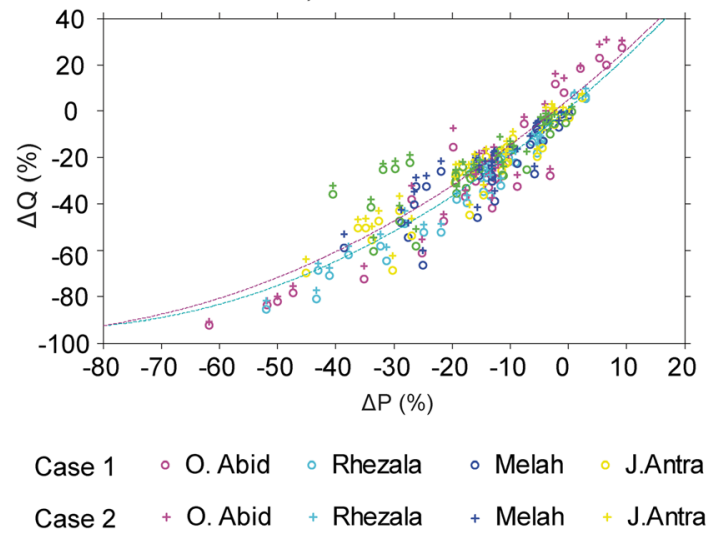

Fig. 5 Elasticity of discharge due to precipitation change for (a) GR4J model and (b) shows elasticity curves (E.C.) from the other hydrological models. $\Delta \mathrm{P}$ and $\Delta \mathrm{Q}$ are the changes in discharge and precipitation from the disagreement between our results and that of Guo et al. (2017) is that their Australian catchments include a greater variety of climate (precipitation ranging between 344 and $1979 \mathrm{~mm}$ ). Rather, under Northern Tunisia's semi-arid climate, the limited water availability heavily constrains AET.

\section{Sensitivity of hydrological projections to potential evapotranspiration estimation}

The use of different PET estimations results in similar hydrological projections, similar elasticity curves, and also constitute a small proportion of the total variance within an ANOVA. This shows the low sensitivity of hydrological projections to PET estimation in Northern Tunisia. This means that it is relatively unimportant which PET formulation is used within hydrological climate change impact assessments for this region, and thus, a simple, temperature-based PET formel would be sufficient. To this extent, a bias in PET due to the use of such a formula would not have an important cumulative impact on the hydrological projections.

In arid regions, AET is highly limited by water availability, which limits the hydrological impact of any change in PET. The behaviour of AET, which is shown to increase with decreasing temperature (Fig. 3), could be explained by the negative correlation between precipitation and temperature in Northern Tunisia, e.g. dry years are associated with warm periods and wet years to cold periods. The opposite trends for the changes of AET and PET and the positively correlated change of AET and precipitation, under present and future climate conditions, indicate that precipitation is the main driver for AET in this region, and we confirm that the study catchments are water-limited rather than energy-limited.

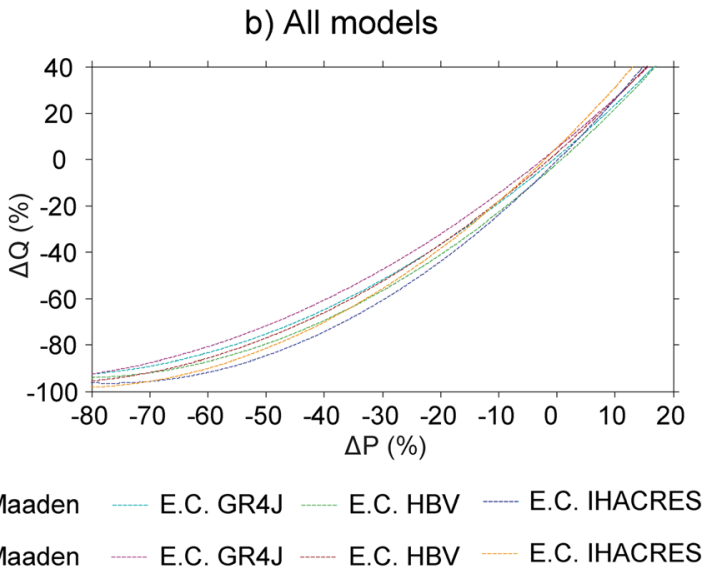

different rainfall-runoff models, catchments, representative concentration pathway scenarios (RCPs), climate models (GCM-RCMs), time periods and potential evapotranspiration estimation cases 


\section{Impact of climate change on the hydroclimatology of Northern Tunisia}

This study provides a first quantification on the impact of climate change on the discharge in Northern Tunisia. Our results show a significant future decrease in discharge due to a decrease in rainfall; this relationship is amplified because of the high elasticity of runoff to rainfall in this region. These results point to a situation of critical water stress in the future given that Tunisia already suffers from water paucity and is considered to be a water-poor country (Blinda and Thivet 2009). In this context, it seems that the competition between the ecological water requirements of wetlands with human uses will increase. The expected decrease of discharge, decrease of precipitation and increase of PET are factors that favour a future increase of salinity of the Lake Ichkeul. According to Hamdi et al. (2012), any change in the salinity pattern of the lake and its fresh water supply could affect negatively the available food of herbivorous waterbirds (mainly Potamogeton and Scirpus consumed by ducks and coots) and could affect the abundance of the waterbird communities. These results motivate adaption strategies for future climatic conditions, especially for the management of surface water resources and to ensure the ecological water requirement of wetland, a vital interest in the preservation of biodiversity.

\section{Limitations}

We recognize that the projected PET, if calculated by a physically based formula such as Penman-Monteith, could be larger than the PET projected by a temperature-based formula, or lower than the present PET condition, which means that it is possible that cases 1 and 2 may not envelop all the possible realizations of PET. Evaporative demand depends mainly on four major physical variables: air temperature, vapour pressure, net radiation and wind speed. Temperature-based formulae consider only one of these variables: temperature. A substantial change in vapour pressure and/or increase of net radiation and/or increase of wind speed that accompanies the expected future increase in temperature could generate a possible increase in PET greater than that projected by temperaturebased formula. Hence, any future increase of vapour pressure and others could compensate the increase in PET and could generate a decrease in PET compared with the present condition, as found for example in the pan evaporation paradox. According to Guo et al. (2017), who evaluated the sensitivity of PET to different climate drivers under different climate conditions in Australian catchments, PET is generally more sensitive to perturbations in temperature than to the other climate variables. In addition, they found that discharge generally shows a higher sensitivity to perturbations in temperature. In the case of the current study, while the temperature is the primary driver of PET, its change does not affect projected discharge to a large extent. We can therefore expect that the effect of perturbations in other climate variables would have a smaller impact compared with temperature. In addition, the future change in these variables could compensate each other. Wang et al. (2017) noticed for example that for several Chinese catchments, the decrease in relative humidity together with the negative contribution of wind speed are strong enough to neutralize the warming signal, leading to a strengthening in evaporative demand, over the period 1994-2014, in some regions.

\section{Conclusion}

The methods proposed in this study were developed in order to simulate the impact of PET estimation in a data-scarce region, which could otherwise not support the data requirements for a full PET formulation comparison. We conclude that for Northern Tunisia, and for similar regions, a simple temperature-based PET formulation is sufficient for hydrological projections. The uncertainty introduced by the PET estimation is minimal compared with uncertainty stemming from RRM structure, RCP scenario and the GCM-RCM structure. While we acknowledge that the effect of PET estimation might be different for other regions and climatic regimes, these results confirm that the choice of any particular PET estimation method has a limited impact on discharge simulations for semi-arid catchments. This study shows that data scarcity in developing countries may not hinder creating reliable hydrological projections. This work may facilitate further investigation into the impact of climate change on Northern Tunisia's water resources, as well as for other data-scarce, arid regions.

Acknowledgements This work is part of the postdoctoral research of the first author at the University of Zurich, Switzerland, which was supported by a Swiss Government Excellence Scholarship. The authors are grateful to INM (Institut National de la Météorologie) and to DGRE (Direction Générale des Ressourcesen Eau) in Tunisia for providing the necessary hydro-climatic data for this study. We also recognize the EUROCORDEX community for the provision of climate modelled data. We thank Dr. Urs Beyerle for his assistance with the retrieval of EUROCORDEX data. We also thank Dr. Christopher Reyer and Dr. Christophe Randin for their valuable comments, which helped to improve the manuscript.

Funding Information Open access funding provided by Swedish University of Agricultural Sciences.

Open Access This article is licensed under a Creative Commons Attribution 4.0 International License, which permits use, sharing, adaptation, distribution and reproduction in any medium or format, as long as you give appropriate credit to the original author(s) and the source, provide a link to the Creative Commons licence, and indicate if changes were made. The images or other third party material in this article are included in the article's Creative Commons licence, unless indicated 
otherwise in a credit line to the material. If material is not included in the article's Creative Commons licence and your intended use is not permitted by statutory regulation or exceeds the permitted use, you will need to obtain permission directly from the copyright holder. To view a copy of this licence, visit http://creativecommons.org/licenses/by/4.0/.

\section{References}

Abbaris A, Dakhlaoui H, Thiria S, Baragaoui Z (2014) Variational data assimilation with the YAO platform for hydrological forecasting evolving water resources systems. In: Understanding, Predicting and Managing Water-Society Interactions, vol 364. IAHS Publ, pp 1-6. https://doi.org/10.5194/piahs-364-3-2014

Addor N, Rössler O, Köplin N, Weingartner R, Seibert J (2014) Robust changes and sources of uncertainty in the projected hydrological regimes of Swiss catchments. Water Resour Res 50(10):75417562. https://doi.org/10.1002/2014WR015549

Andréassian V, Perrin C, Michel C (2004) Impact of imperfect potential evapotranspiration knowledge on the efficiency and parameters of watershed models. J Hydrol 286:19-35. https://doi.org/10.1016/j. jhydrol.2003.09.030

Aouissi J, Benabdallah S, Chabaane Z, Cudennec C (2016) Evaluation of potential evapotranspiration assessment methods for hydrological modelling with SWAT - application in data-scarce rural Tunisia. Agric Water Manag 174. https://doi.org/10.1016/j.agwat.2016.03. 004

Ben Fraj W, Elloumi M, Molle F (2019) The politics of interbasin transfers: socio-environmental impacts and actor strategies in Tunisia. Nat Res Forum 43:17-30. https://doi.org/10.1111/1477-8947.12165

Bae D-H, Jung I-W, Lettenmaier DP (2011) Hydrologic uncertainties in climate change from IPCC AR4 GCM simulations of the Chungju Basin. Korea J Hydrol 401(1-2):90-105. https://doi.org/10.1016/j. jhydrol.2011.02.012

Bargaoui Z, Dakhlaoui H, Houcine A (2008) Modélisation pluie-débit et classification hydroclimatique. Rev Sci Eau 21:233-245. https://doi. org/10.7202/018468ar

Blinda M, Thivet G (2009) Ressources et demandes en eau en Méditerranée : situation et perspectives. Sécheresse 20:9-16. https://doi.org/10.1684/sec.2009.0162

Brigode P, Oudin L, Perrin C (2013) Hydrological model parameter instability: a source of additional uncertainty in estimating the hydrological impacts of climate change? J Hydrol 476:410-425. https:// doi.org/10.1016/j.jhydrol.2012.11.012

Chen J, Brissette FP, Chaumont D, Braun M (2013) Finding appropriate bias correction methods in downscaling precipitation for hydrologic impact studies over North America. Water Resour Res 49(7):41874205. https://doi.org/10.1002/wrcr.20331

Coron L, Andréassian V, Perrin C, Lerat J, Vaze J, Bourqui M, Hendrickx F (2012) Crash testing hydrological models in contrasted climate conditions: an experiment on 216 Australian catchments. Water Resour Res 48:W05552. https://doi.org/10.1029/2011WR011721

Cramer W, Guiot J, Fader M, Garrabou J, Gattuso JP, Iglesias A, Lange MA, Lionello P, Llasat MC, Paz S, Peñuelas J, Snoussi M, Toreti A, Tsimplis MN, Xoplaki E (2018) Climate change and interconnected risks to sustainable development in the Mediterranean. Nat Clim Chang 8:972-980. https://doi.org/10.1038/s41558-018-0299-2

Dakhlaoui H, Bargaoui Z, Bárdossy A (2009) Comparaison de trois méthodes d'usage de la technique des voisins les plus proches en vue d'amélioration de la performance de l'algorithme SCE-UA appliqué pour le calage du modèle pluie-débit HBV. In: Hydroinformatics in Hydrology, Hydrogeology and Water Resources, vol 331. IAHS Publ, pp 139-153
Dakhlaoui H, Bargaoui Z, Bárdossy A (2012) Toward a more efficient calibration schema for HBV rainfall-runoff model. J Hydrol 444 445:161-179. https://doi.org/10.1016/j.jhydrol.2012.04.015

Dakhlaoui H, Ruelland D, Tramblay Y, Bargaoui Z (2017) Evaluating robustness of conceptual rainfall-runoff models under climate variability in Northern Tunisia. J Hydrol 550:201-217. https://doi.org/ 10.1016/j.jhydrol.2017.04.032

Dakhlaoui H, Ruelland D, Trambaly Y (2019) A bootstrap-based differential split-sample test to assess the transferability of conceptual rainfall-runoff models under past and future climate variability. J Hydrol. https://doi.org/10.1016/j.jhydrol.2019.05.056

Duan QY, Sorooshian S, Gupta V (1992) Effective and efficient global optimization for conceptual rainfall-runoff models. Water Resour Res 28:1015-1031. https://doi.org/10.1029/91WR02985

Fowler A (2002) Assessment of the validity of using mean potential evaporation in computations of the long-term soil water balance. J Hydrol 256:248-263. https://doi.org/10.1016/S0022-1694(01) 00542-X

Fowler KJ, Peel MC, Western AW, Zhang L, Peterson TJ (2016) Simulating runoff under changing climatic conditions: revisiting an apparent deficiency of conceptual rainfall-runoff models. Water Resour Res 52(3):1820-1846. https://doi.org/10.1002/ 2015WR018068

Gupta HV, Kling H, Yilmaz KK, Martinez GF (2009) Decomposition of the mean squared error and NSE performance criteria implications for improving hydrological modelling. J Hydrol 377:80-91. https:// doi.org/10.1016/j.jhydrol.2009.08.003

Guo D, Westra S, Maier HR (2017) Impact of evapotranspiration process representation on runoff projections from conceptual rainfall-runoff models. Water Resour Res 53:435-454. https://doi.org/10.1002/ 2016WR019627

Hakala K, Addor N, Teutschbein C, Vis M, Dakhlaoui H, Seibert J (2019) Hydrological climate change impact modeling. In: Maurice P (ed) Encyclopedia of water: science, technology, and society. https://doi. org/10.1002/9781119300762.wsts0062

Hamdi N, Touihri M, Charfi F (2012) Diagnostic Ecologique du parc National Ichkeul (Tunisie) après la construction des barrages; Cas des oiseaux d'eaux. Revue d'écologie 67(1):41-62

Hartmann G, Bárdossy A (2005) Investigation of the transferability of hydrological models and a method to improve model calibration. Adv Geosci 5:83-87. https://doi.org/10.5194/adgeo-583-2005

Hawkins E, Sutton R (2009) The potential to narrow uncertainty in regional climate predictions. Bull Am Meteorol Soc 90(8):10951107. https://doi.org/10.1175/2009BAMS2607.1

Henia L (2008) (directed by) Atlas de l'eau en Tunisie. Publication de la Faculté des Sciences Humaines et Sociales, Tunis

Institut Tunisien des Etudes Stratégiques (2014) Système Hydraulique de la Tunisie à l'horizon 2030. Tunisia 222 pp.

IPCC - Intergovernmental Panel on Climate Change (2013) Climate Change 2013: The physical science basis. Contribution of Working Group I to the Fifth Assessment Report of the Intergovernmental Panel on Climate Change. In: Stocker TFD, Qin G-K, Plattner M, Tignor SK, Allen J, Boschung A, Nauels Y, Xia V, Bex, Midgley PM (eds) . Cambridge University Press, Cambridge $1535 \mathrm{pp}$.

Jabloun M, Sahli A (2008) Evaluation of FAO-56 methodology for estimating reference evapotranspiration using limited climatic dataapplication to Tunisia. Agric Water Manag 95:707-715. https:// doi.org/10.1016/j.agwat.2008.01.009

Jakeman AI, Littlewood IG, Withehead PG (1990) Computation of the instantaneous unit hydrograph and identifiable component flows with application to two small upland catchments. J Hydrol 117:275-300. https://doi.org/10.1016/0022-1694(90) 90097-H 
Kingston DG, Todd MC, Taylor RG, Thompson JR, Arnellet NW (2009) Uncertainty in the estimation of potential evapotranspiration under climate change. Geophys Res Lett 36:L20403. https://doi.org/10. 1029/2009GL040267

Klemeš V (1986) Operational testing of hydrological simulation models. Hydrol Sci J 31:13-24. https://doi.org/10.1080/ 02626668609491024

Li Z, Chen Y, Shen Y, Liu Y, Zhang S (2013) Analysis of changing pan evaporation in the arid region of Northwest China. Water Resour Res 2013(49):2205-2212. https://doi.org/10.1002/wrcr.20202

Lindström G, Johanson B, Gardelin MPM, Bergström S (1997) Development and test of the distributed HBV-96 hydrological model. J Hydrol 201:272-288. https://doi.org/10.1016/S0022-1694(97) 00041-3

Mansour M, Hachicha M, Mougou A (2017) Trend analysis of potential evapotranspiration case of Chott-Meriem region (the Sahel of Tunisia). Int J Agric Innov Res 5:703-708. https://doi.org/10. 1016/j.agwat.2015.12.004

Marchane A, Tramblay Y, Hanich L, Ruelland D, Jarlan L (2017) Climate change impacts on surface water resources in the Rheraya catchment (High-Atlas, Morocco). Hydrol Sci J. https://doi.org/10.1080/ 02626667.2017.1283042

Meinshausen M, Smith SJ, Calvin K et al (2011) The RCP greenhouse gas concentrations and their extensions from 1765 to 2300 . Clim Chang:109-213. https://doi.org/10.1007/s10584-011-0156-Z

Nash JE, Sutcliffe JV (1970) River flow forecasting through conceptual models-part I: a discussion of principles. J Hydrol 10:282-290. https://doi.org/10.1016/0022-1694(70)90255-6

Oudin L, Michel C, Anctil F (2005a) Which potential evapotranspiration input for a lumped rainfall-runoff model? Part 1-can rainfall-runoff models effectively handle detailed potential evapotranspiration inputs? J Hydrol 303:275-289. https://doi.org/10.1016/j.jhydrol.2004. 08.025

Oudin L, Hervieu F, Michel C, Perrin C, Andréassian V, Anctil F, Loumagne C (2005b) Which potential evapotranspiration input for a lumped rainfall-runoff model? Part 2: towards a simple and efficient potential evapotranspiration model for rainfall-runoff modelling. J Hydrol 303:290-306. https://doi.org/10.1016/j.jhydrol.2004. 08.026

Perrin C, Michel C, Andréassian V (2003) Improvement of a parsimonious model for streamflow simulation. J Hydrol 279:275-289. https://doi.org/10.1016/S0022-1694(03)00225-7

Prudhomme C, Williamson J (2013) Derivation of RCM-driven potential evapotranspiration for hydrological climate change impact analysis in Great Britain: a comparison of methods and associated uncertainty in future projections. Hydrol Earth Syst Sci 17:1365-1377. https://doi.org/10.5194/hess-17-1365-2013

Ruelland D, Hublart P, Tramblay Y (2015) Assessing uncertainties in climate change impacts on runoff in Western Mediterranean basins. In: Hydrologic non-stationarity and extrapolating models to predict the future, vol 371. IAHS Publ, pp 75-81. https://doi.org/10.5194/ piahs-371-75-2015
Seibert J (2003) Reliability of model predictions outside calibration conditions. Nord Hydrol 34:477-492. https://doi.org/10.2166/nh.2003. 028

Seiller G, Anctil F (2014) Climate change impacts on the hydrologic regime of a Canadian river: comparing uncertainties arising from climate natural variability and lumped hydrological model structures. Hydrol Earth Syst Sci 18:2033-2047. https://doi.org/10. 5194/hess-18-2033-2014

Seiller G, Anctil F (2016) How do potential evapotranspiration formulas influence hydrological projections? Hydrol Sci J. https://doi.org/10. 1080/02626667.2015.1100302

Sellami H, Benabdallah S, La Jeunesse I, Vanclooster M (2015) Quantifying hydrological responses of small Mediterranean catchments under climate change projections. Sci Total Environ 543:924936. https://doi.org/10.1016/j.scitotenv.2015.07.006

Sheffield J, Wood EF, Roderick ML (2012) Little change in global drought over the past 60 years. Nature 491:435-438. https://doi. org/10.1038/nature11575

Sperna Weiland FC, Tisseuil C, Dürr HH, Vrac M, Beek LPHV (2012) Selecting the optimal method to calculate daily global reference potential evaporation from CFSR reanalysis data for application in a hydrological model study. Hydrol Earth Syst Sci 2012(16):9831000. https://doi.org/10.5194/hess-16-983-2012

Terink W, Immerzeel WW, Droogers P (2013) Climate change projections of precipitation and reference evapotranspiration for the Middle East and Northern Africa until 2050. Int J Climatol 33: 3055-3072. https://doi.org/10.1002/joc.3650

Teutschbein C, Seibert J (2012) Bias correction of regional climate model simulations for hydrological climate-change impact studies: review and evaluation of different methods. J Hydrol 456-457:11-29. https://doi.org/10.1016/j.jhydrol.2012.05.052

Tramblay Y, Ruelland D, Hanich L, Dakhlaoui H (2016) Hydrological impacts of climate change in north African countries. Sub-chapter 2.3.1, The Mediterranean region under climate change. A scientific update, IRD Éditions, $736 \mathrm{p}$

Tramblay Y, Jarlan L, Hanich L, Somot S (2017) Future scenarios of surface water resources availability in North African dams. Water Resour Manag 32:1291-1306. https://doi.org/10.1007/s11269-017$1870-8$

Vormoor K, Heistermann M, Bronstert A, Lawrence D (2018) Hydrological model parameter (in)stability-"crash testing" the HBV model under contrasting flood seasonality conditions. HSJ 63:991-1007. https://doi.org/10.1080/02626667.2018.1466056

Wang T, Zhang J, Sun F, Liu W (2017) Pan evaporation paradox and evaporative demand from the past to the future over China: a review. WIREs Water 4:e1207. https://doi.org/10.1002/wat2.1207

Wilcox BP, Seyfried MS, Breshears DD, Stewart BA, Howell TA (2003) The water balance on rangelands. In: Encyclopedia of Water Science, vol 791-4. Marcel Dekker, New York

Publisher's note Springer Nature remains neutral with regard to jurisdictional claims in published maps and institutional affiliations. 